\title{
A rapid assessment of the impact of COVID-19 on the utilization of hospital services in Ondo State of South Western Nigeria
}

Mahmud Zubairu Mahmud ( $\nabla$ mahmudisnow@gmail.com )

Research article

Keywords: COVID-19, lockdown, Hospital services, Respiratory Tract Infections \& Morbidity

Posted Date: October 27th, 2021

DOl: https://doi.org/10.21203/rs.3.rs-966817/v1

License: (c) (i) This work is licensed under a Creative Commons Attribution 4.0 International License.

Read Full License 


\section{Abstract \\ Background}

There is no doubt that COVID_19 has impacted on all facets of human activities everywhere, including ONDO state, Nigeria. However, empirical evidence of the extent of this impact in ONDO is lacking. The objective of this study was to evaluate the impact of COVID_19 epidemic on the utilization of hospital services \& determine the existence of community transmission of COVID_19 in ONDO state using a proxy "Respiratory Tract Infections, RTIs".

\section{Methods}

The study used resident clinicians to conduct peer review of hospital utilization records. The review was retrospectively for the months of January to May for four consecutive years (2018 to 2021). The team reviewed outpatient records from 11 health facilities before the advent of COVID_19 (2018) to date (2021). Thousands of such records were scrutinized to reveal six parameters: number of antenatal visits; number of live births and total number of infants served BCG; number RDTs conducted for Malaria, number of RTIs seen and total number of patients for all other illnesses.

\section{Results}

Results showed a decline in all parameters investigated except RTIs. Indeed, the proportion of RTIs related hospital visits increased by about $22.8 \%$.

\section{Discussion}

The decline in the utilization of hospital services is expected given the lock down measures implemented to halt transmission of COVID_19 that makes it difficult to access health facilities. The rise in the incidence of RTIs may probably be that, they were COVID cases that were undetected due to limited COVID_19 testing capacity.

\section{Conclusion}

The study concludes that COVID_19 epidemic impacted negatively on all aspect of hospital services except RTIs. The increment is statistically significant. As the most prominent of all symptoms of COVID_19 presents as respiratory tract disorder, a continued rise in RTIs despite declining rates of confirmed COVID19 cases in the state at the moment suggests that, there's an ongoing community transmission. 


\section{Background}

Ondo state is one of 36 states of the federal republic of Nigeria. It is situated in the western part of the country where rainfall is often very high, in the range of about 91.6 to $151.7 \mathrm{~mm}$ per annum (Adebayo 0 Eludoyin et al 2016). The ambient temperature is equally high too $\left(24.6-26.5^{\circ} \mathrm{C}\right.$ monthly average) and tends to favor the transmission of infectious diseases. The state has an estimated landmass area of about $15,500 \mathrm{KM}^{2}$ that is further decimated into other smaller areas called local government areas (LGAs). There are 18 of such LGAs and they serve as the last of 3 tiers of government in Nigeria. In Nigeria, the LGAs are the most fundamental unit of government. According to year 2016 projected national census, (Demographic statistics bulletin of Nigeria 2017) nearly 5million persons live in Ondo state. The persons are mostly agrarian \& reside in the rural areas practicing agriculture. The health system in the state consists of about 623 Primary Health Care Centers (PHCs) and 22 referral centers spread across all 18LGAs. (Records from the Department of Planning, Research \& Statistics of Ondo State Ministry of Health) Several hundreds of health workers including physicians provide health care services at the PHCs or referral centers (hospitals). All services such as conducting RDT for Malaria, taking birth delivery, immunization etc. rendered are manually entered into outpatient department (OPD) hospital registers which in turn are transcribed electronically into the District Health Information System (DHIS2) platform the national server.

The first case of COVID_19 arrived in the state on March 30th, 2020 - just barely less than a month of the index case in Nigeria that was seen in Lagos on 27th of February 2020. It was recorded in Akure south LGA amongst an Indian returnee soldier in a military formation (Daily COVID_19 SITREP, World Health Organization field office, Akure Nigeria). Since then, roughly 3,239 of confirmed cases have been recorded, spread across all 18 LGAs (Year 2020 Week 53 TC update/SITREP document, Ondo field WHO field office). Indeed, in the year 2020, the state experienced a first wave of the epidemic (spanning between April and September) and is presently witnessing a second one according to epidemiological data from the ministry of health. During the first phase of the epidemic, three LGAs namely OWO, AKURE NORTH \& AKURE SOUTH stood out clearly as the most affected areas. The 3 LGAs are the commercial nerve centers of the state and apparently share strong transportation and trade links with the high risk state of Lagos. They accounted for nearly $80 \%$ of the total number of cases seen in the entire state. (Year 2020 Week 53 TC update/SITREP document, Ondo State WHO field office) The viral spread in Akure south for instance was so alarming that, at a point in time (27th epidemic week TC/SITREP, year 2020) laboratory test positivity as high as $24 \%$ was recorded. In other words, about 24 persons of all 100 persons tested in Akure south were COVID positive. In order to check further spread, the state government responded by strictly enforcing basic infection control and prevention measures collectively packaged as the national COVID_19 control protocols. These included 'city lockdowns' (which implied limited travels of all persons, closure of nonessential businesses \& social distancing etc.) and the use of nonpharmaceutical approaches like regular hand washing, use of face masks (PPEs) and so on. Unfortunately, the measures came with attendant negative consequences on all facets of life and have been extensively investigated. The nation's economy began to nose dive. Many people became poorer 
and incapable of feeding themselves because they depended on daily paid jobs which were hampered by COVID control measures. Accordingly, the general health status of a vast majority of people deteriorated due to malnutrition, stress, lack of exercise and so on. Kwa Andan et al 2020 showed that COVID_19 pandemic in Nigeria brought about a fall in total GDP by $23 \%$. Henry Inegbedion in 2021 also demonstrated that COVID_19 induced lockdown significantly constrained economic activities and circular flow of incomes. Temiloluwa et al in 2020 reported a case of Tuberculous neuroretinitis and how COVID_19 lockdown worsened its prognosis. Nwoke et al 2020 wrote on the impact of COVID_19 lockdown on consumers' access to essential medicines and that $35.2 \%$ of the respondents managing chronic illnesses had difficulties in accessing essential medicines during lockdowns. Ahmed et al 2021 investigated the effect of COVID_19 on MNCH services. He found out that there was a reduction in utilization of basic Maternal, Newborn and Child Health MNCH services such as antenatal care and routine immunization. Godwin et al corroborated Ahmed's finding in a different study on MNCH services. The studies on the impact of COVID_19 are really copious. The essence of this current study is to add to scientific knowledge by providing information regarding how hospital services fared during the COVID era in Akure south LGA of Ondo state. The study also aims to determine the existence of community transmission of the disease using a proxy "Respiratory Tract Infections, RTIs". The following would be tested to show the existence of any community transmission of COVID-19.

Null hypothesis: There's no statistically significant difference in the proportion of persons suffering from RTIs in the first and second waves COVID_19 epidemic in Akure south LGA.

Alternative hypothesis: There is a statistically significant difference in the proportion of persons suffering from RTIs in the first and second waves COVID_19 epidemic in Akure south LGA.

\section{Methods}

The study used resident clinicians (facility managers) to obtain data on hospital attendance in Akure south LGA. 11 health facilities were randomly selected from a total of $47 \mathrm{HFs}$ available in the LGA. Firstly, the names of all routine immunization serving health facilities available in the LGA were recorded - each on a piece of paper; the paper squeezed into a small ball \& tossed in air for selection by the principal researcher. The selection was such that, only one health facility was recruited per ward into the study. An initial planning and sensitization meeting was conducted for all facility managers during which participants were trained on how to conduct retrospective records search. The procedure was simply to count the number of times a study parameter (number of antenatal visits; number of live births and total number of infants served BCG; number RDTs conducted for Malaria, number of RTIs seen and total number of patients for all other illnesses) featured on every page of the outpatient register of the hospital. In the study, the team reviewed records from O.P.D registers in the facilities retrospectively from 2018 to the year 2021. Specifically, the review was for the months of January to May of each of the study years. For fairness and reduction of bias, each clinician reviewed data not from his resident health facility but from the nearest one in a different ward (a peer review). Table 1 shown below was completed to document the findings at the health facilities. These finding were analyzed in the form of frequencies, 
graphs, tables and percentages to reveal the trends. And in order to find any statistically significant difference between results obtained before the COVID_19 era and during the COVID_19 epidemic periods, the z-test statistics for proportions was employed.

Table1. Primary data collection tool for retrospective records search

\begin{tabular}{|c|c|c|c|c|c|c|c|}
\hline Year & $\begin{array}{l}\text { Months } \\
\text { of the } \\
\text { year }\end{array}$ & $\begin{array}{l}\text { Tot no. of } \\
\text { children } \\
\text { served BCG } \\
\text { vaccine }\end{array}$ & $\begin{array}{l}\text { Tot } \\
\text { no. } \\
\text { of } \\
\text { RTI } \\
\text { seen }\end{array}$ & $\begin{array}{l}\text { Tot no. of } \\
\text { patients (for } \\
\text { all purposes) } \\
\text { seen }\end{array}$ & $\begin{array}{l}\text { Tot no. of } \\
\text { antenatal } \\
\text { visits } \\
\text { recorded }\end{array}$ & $\begin{array}{l}\text { Tot no. of } \\
\text { RDT for } \\
\text { malaria } \\
\text { recorded }\end{array}$ & $\begin{array}{l}\text { Tot no. } \\
\text { of births } \\
\text { recorded }\end{array}$ \\
\hline \multirow[t]{5}{*}{2018} & January & & & & & & \\
\hline & February & & & & & & \\
\hline & March & & & & & & \\
\hline & April & & & & & & \\
\hline & May & & & & & & \\
\hline \multirow[t]{5}{*}{2019} & January & & & & & & \\
\hline & February & & & & & & \\
\hline & March & & & & & & \\
\hline & April & & & & & & \\
\hline & May & & & & & & \\
\hline \multirow[t]{5}{*}{2020} & January & & & & & & \\
\hline & February & & & & & & \\
\hline & March & & & & & & \\
\hline & April & & & & & & \\
\hline & May & & & & & & \\
\hline \multirow[t]{5}{*}{2021} & January & & & & & & \\
\hline & February & & & & & & \\
\hline & March & & & & & & \\
\hline & April & & & & & & \\
\hline & May & & & & & & \\
\hline
\end{tabular}


The detailed result that was obtained in the study is available in figure 1. Generally, they are presented in table of frequencies, graphs and percentages summarized as 7 major headings ( $A-G)$ that are outlined below.

Result A: Baseline values. COVID_19 disease began in the state in the year 2020, precisely March 2020. Thus, all values obtained in the study prior to this period - specifically in the year 2019 are regarded as baseline values. These are summarized in table 2 below.

Table2. Core baseline values

\begin{tabular}{|lll|}
\hline S/N & Parameter & $\begin{array}{l}\text { Baseline (value as at 2019, pre COVID19 era) absolute } \\
\text { numbers recorded }\end{array}$ \\
\hline 1 & Number of infants served BCG & 2,221 \\
\hline 2 & $\begin{array}{l}\text { Number of patients presenting as } \\
\text { RTIs }\end{array}$ & 1,042 \\
\hline 3 & $\begin{array}{l}\text { Total number patients seen in } \\
\text { attendance register }\end{array}$ & 44,534 \\
\hline 4 & Number of Antenatal visits & 10,811 \\
\hline 6 & $\begin{array}{l}\text { Number of RDT done for malaria } \\
\text { Number of New born babies }\end{array}$ & 6,949 \\
\hline
\end{tabular}

Results B1: BCG vaccination. The state witnessed a progressive decrease in the number of infants immunized with BCG vaccine during RI sessions from 2018 to date (2021). Figure2 below is the graphical presentation of the trends in BCG immunization coverage seen in Ondo state from year 2018 to 2021.

Results B2: Cumulative BCG immunization coverage January to May. The trend in BCG immunization coverage 2018 to date (2021) is presented in Table 3 below. Data was obtained from the DHIS2 platform

Table3: Cumulative BCG immunization coverage January to May.

\begin{tabular}{|lllll|}
\hline Year & $\mathbf{2 0 1 8}$ & $\mathbf{2 0 1 9}$ & $\mathbf{2 0 2 0}$ & $\mathbf{2 0 2 1}$ \\
\hline \% BCG coverage & 200.7 & 159.8 & 136.5 & 137 \\
\hline
\end{tabular}

Result C1: Trends in respiratory Tract Infections (RTIs) seen in the health facilities. The total number of persons clinically diagnosed to be of RTI etiology is shown in graph3 below. Clearly, between 2018 and 2019 there was a slight increase in RTIs cases only to be followed by a sharp decline up to 2020. In 2021 however, the number of RTIs appear to be on the rise as can be seen in figure3 below.

Result C2: Proportion of all hospital visits by patients that is RTIs. Table 4 presents the $\%$ of all hospital visits observed during the study years to be of RTI etiology. 
Table4. The proportion of all hospital patient visits that is RTIs in the study period

\begin{tabular}{|llll|}
\hline Year & $\begin{array}{l}\text { Tot no. of patients (for all } \\
\text { purposes) seen }\end{array}$ & $\begin{array}{l}\text { Tot no. of RTI } \\
\text { seen }\end{array}$ & $\begin{array}{l}\text { Proportion of all hospital patients that } \\
\text { were RTI (in \%) }\end{array}$ \\
\hline 2018 & 42445 & 1009 & 2.4 \\
\hline 2019 & 44534 & 1042 & 2.3 \\
\hline 2020 & 39563 & 812 & 2.1 \\
\hline 2021 & 37983 & 1091 & 2.9 \\
\hline
\end{tabular}

Results D1: Trends in the total number of patients (for all purposes) that presented at health facilities. The data (figure4 below) shows that there is a sharp decline in hospital visits by patients since 2019 even before the advent of COVID_19 in the state.

Results D2: Proportion of total population that sought health care services on yearly basis. This is the absolute number of outpatients recorded each year divided by the estimated total population for the year. Table 5 is the results obtained in the study. The denominators were sourced from 2006 projected national census (National Bureau of Statistic, 2006 Nigeria)

Table5: Proportion of total population which sought health care services during the study period.

\begin{tabular}{|llll|}
\hline Year & $\begin{array}{l}\text { Projected total } \\
\text { population (2006 } \\
\text { census) }\end{array}$ & $\begin{array}{l}\text { Total number of patients } \\
\text { (for all purposes) seen }\end{array}$ & $\begin{array}{l}\text { Proportion of total population that } \\
\text { sort health care services }\end{array}$ \\
\hline 2018 & 503,594 & 42,445 & 8.4 \\
\hline 2019 & 518,702 & 44,534 & 8.6 \\
\hline 2020 & 534,263 & 39,563 & 7.4 \\
\hline 2021 & 550,291 & 37,983 & 6.9 \\
\hline
\end{tabular}

Results E1: Trends in antenatal visits. As can be seen in from the data as well as figure 5 below, there is a decline in antenatal visits since the advent of COVID_19.

Results E1: Proportion of all hospital visits that is Antenatal. Table6 is a presentation of the \% antenatal of all hospital visits through the years.

Table6: Proportion of all hospital visits that were for antenatal purposes. 


\begin{tabular}{|llll|}
\hline Year & $\begin{array}{l}\text { Total number of patients } \\
\text { (for all purposes seen) }\end{array}$ & $\begin{array}{l}\text { Total number of } \\
\text { antenatal visits } \\
\text { recorded }\end{array}$ & $\begin{array}{l}\text { Proportion of all hospital visits that } \\
\text { were of antenatal purposes (in \%) }\end{array}$ \\
\hline 2018 & 42445 & 9882 & 23.3 \\
\hline 2019 & 44534 & 10811 & 24.3 \\
\hline 2020 & 39563 & 9488 & 24.0 \\
\hline 2021 & 37083 & 9354 & 24.6 \\
\hline
\end{tabular}

Results F1: Trends in total number of RDTs recorded. This implied rapid diagnostic tests for Malaria. It does not necessarily mean confirmed Malaria cases seen in the health facilities as both positive and negative RDT results are in included in this set. The result that was obtained from the study is shown in figure 6 below.

Results F2: Proportion of all hospital visits that conducted RDT done. The presentation of the proportion of all hospital visits that had RDT conducted for them during the study years is provided in table7 below.

Table7: Proportion of all hospital visits that had RDT conducted.

\begin{tabular}{|llll|}
\hline Year & $\begin{array}{l}\text { Tot no. of patients (for } \\
\text { all purposes) seen }\end{array}$ & $\begin{array}{l}\text { Tot no. of RDT for } \\
\text { malaria recorded }\end{array}$ & $\begin{array}{l}\text { Proportion of all hospital patients that } \\
\text { had RDT for Malaria (in \%) }\end{array}$ \\
\hline 2018 & 42445 & 6330 & 14.9 \\
\hline 2019 & 44534 & 6949 & 15.6 \\
\hline 2020 & 39563 & 6092 & 15.4 \\
\hline 2021 & 37983 & 5056 & 13.3 \\
\hline
\end{tabular}

Results G1: Trends in live births recorded. Figure7 below refers to the total number of live births recorded during the study period.

\section{Discussions}

In Ondo state, COVID_19 epidemic period began from the year 2020 - at the tail end of March (30th of March) to be precise when the first confirmed case of the disease was detected. Thus, all data concerning the utilization of hospital services collected in the study before this period can be regarded as baseline values. In the study, this refers to all data collected in the year 2019. Consequently all analysis on trends and even statistical analysis performed to interpret the study results in this paper focus on year 2019 as reference point. Table2 is pertinent as it gives the core values of all 6 parameter in Ondo state prior to the advent of COVID_19. Two epidemic waves of COVID_19 were actually seen in the state. The first wave coincided with the period March 2020 to September 2020 and the other spanned February 2021 to date (June 2021). In the study, any increment or decline in values of all 6 investigated parameters (namely 
number of antenatal visits; number of live births and total number of infants served BCG; number RDTs conducted for Malaria, number of RTIs seen and total number of patients for all purposes) between 2018 and year 2019 cannot be attributed to COVID_19. They are probably due to other factors which operated in the pre-COVID_19 era and are not explored in this study. Generally, in the study, all parameters show a decline in the first wave of the epidemic and continue to do so up to the second wave. This is graphically shown in figures 1 to figure 7 above. However, during the second wave of the epidemic period (February to May 2021), a steep rise in the number of RTIs was noticed amidst a continued decline of all other parameters. This is clearly seen in figure 3 above. The declining trend in every other parameter investigated was not unexpected. It is in total agreement with common local assumption that, COVID_19 impacted negatively on all facets of life and findings from several scholars including Benhard et al 2021 and Hoyer et al 2020. The argument as to how and why COVID_19 negatively affects all shades of health care service delivery in underdeveloped nations like Nigeria is simple: Usually, city lock downs entail restricted movements of persons. During lockdowns, very few vehicle or motorcycles are permitted to ply the roads. Accesses to health facilities for most purposes are limited except for really very serious matters. Consequently, most people only visit health clinics when they necessarily must do so as in life and death matters.

The decline in BCG, antennal visits, births, RDT for Malaria and total hospital attendance are all inter related/interwoven. As explained earlier, COVID_19 pandemic came with city lock down measures which limited logistic or movement of persons. Fewer numbers of pregnant women attend antennal visits and thereafter proceed to deliver in hospitals. Consequently, fewer number of children get served BCG which is the first vaccine delivered at birth by the national immunization schedule of the country.

As for the rise in RTIs during the second epidemic, perhaps there is a subtle increase in COVID_19 infection in the study area. The paucity of laboratory tests renders this impossible to confirm though. RTIs initially declined upon the inception of COVID_19 in 2020 (during the first wave) and then began to rise in 2021 in the second wave of the epidemic. In 2020, the fear of COVID_19 stigmatization supposedly made people having classical symptoms of RTIs (coughs sneeze and sore throat) to 'run away' from hospitals. There was also better compliance to the wearing of face marks and regular washing of hands in the society because COVID disease was 'freshly' new. Several writers including Yueling Zhu et al 2020 and Yonatan Oster et al 2020 showed that, the incidence of RT Is declined during first wave of global COVID_19 epidemic. In 2021, the rise in RTIs can either be attributed to the waning stigmatization from COVID_19 (people were no longer shying away from hospitals following terrific Risk Communication \& Community Engagement RCCE measures undertaken by both government and W.H.O) or to a subtle rise in COVID infection itself as a result of 'a community transmission' of the disease. As the most prominent of all symptoms of COVID_19 presents as respiratory tract disorder, it is plausible to suspect COVID_19 transmission going on in a region with poor testing capacity like Ondo state, Nigeria (COVID_19 test per capita of about 0.0045 or 4.5 per 1000) if the incidence of RT ls are on a rise amidst low COVID_19 test positivity rates. Statistical analysis of RTIs data using the z-test statistics for proportions revealed that there is a difference between the proportion of all hospital visits that were RTIs in the year 2020 and that of 2021. 


\section{Conclusion}

The study concludes that, COVID_19 epidemic impacted negatively on the utilization of hospital services in virtually all areas explored. Immunization service delivery (measured by the uptake of BCG), hospital attendance gauged through total number of outpatients visit, antenatal visits, new births recorded \& RDT for Malaria all declined during all waves of the COVID19 epidemic in Akure south LGA. However, the proportion of all hospital visits diagnosed clinically as RTI during the same period showed an increase by about $22.79 \%$. The increment is statistically significant. A value of 3.67 was obtained at $5 \%$ level of significance using the z-test statistics. Thus, the odds are more in favor for the rejection of the 'Null Hypothesis' which states "There's no statistically significant difference in the proportion of persons suffering from RT Is in the first and second waves COVID_19 epidemic in Akure south LGA". Giving that, the most prominent of all symptoms of COVID_19 presents as respiratory tract disorder, the implication of an increased incidence of RTIs in a COVID endemic area (Akure south LGA) that is showing declining \& low rates of confirmed COVID cases (Test positivity of about $5 \%$ ) are grave: there is community transmission of COVID going on but undetected. COVID_19 morbidity is also probably under reported in the area.

\section{RECOMMENDATION:}

In view of the rising number of RTIs observed during the second wave of the COVID epidemic in Akure South, the study area, it would be helpful to explore the proportion of confirmed COVID_19 cases that are RTIs. It is recommended that COVID testing be 'ramped up' earnestly for all RTI-like illnesses.

\section{List Of Abbreviations}

1. O.P.D; Outpatient register

2. RTIs; Respiratory tract infections

3. BCG; Active case search

4. RDT; Rapid Diagnostic Test

5. LGA; Local government area

6. HF; Health facility

\section{Declarations}

Ethics approval and consent to participate: This was not necessary as the exercise was a national activity directed by the federal republic of Nigeria and in particular Ondo State of the federation.

Consent for publication: Not applicable.

Availability of data and materials: I solemnly state that all data accompanying and cited in the study are readily available at the World Health Organization (W.H.O) office in Akure, Ondo State PHCDA, DHIS2 
server (https://dhis2nigeria.org.ng) and are also presented by the corresponding author in the main manuscript as additional supporting files labeled annexes.

Competing interests: None. All authors involved in the study declare that they do not have any competing interests.

Funding: Practically no funds were received from any quarters for the execution of the study. The study merely leverage on a national activity conducted by the WHO to collect and interpret relevant epidemiological data.

Authors' contributions: The principal author (Mahmud Zubairu) contributed majority of the research work including the little funds expended. The remaining 5 are co-authors. Specifically;

1. A.F assisted in the field supervision of records search \& ensured factual recording of information (study data from the health facilities) by establishing a strong monitoring and supervision mechanism. He wrote the methodology section of the research.

2. G.F conducted the training of the study participants. He collated all data from the study health facilities and provided the relevance of the study. He wrote the recommendation part.

3. O.A scanned the entire draft manuscript. He did the section on the conclusions drawn from the study.

4. M.M provided some explanation as to the significance of RTIs increase observed in the study. He tested the hypothesis.

5. K.T did the section on geo-spatial mapping of the study area and 'combed' the entire manuscript grammatically.

Acknowledgement: Firstly, all glory is to God - the Lord of all the 'worlds'. We thank Him for giving us good health to conclude the study within a relatively short period of time, one month! It was really a very big challenge considering the ongoing mass COVID_19 vaccination campaign at the time and the fear that, the principal researcher's contract with the W.H.O would expire before the conclusion of the study. Many of the study participants were also engaged in the COVID_19 mass vaccination exercise and so, there wasn't enough time for anything. Luckily, all worked tirelessly; the research was concluded as scheduled \& the principal researcher's contract was also renewed. Therefore, we thank God for that.

We thank also Dr. Terna Nomhwange, the COVID_19 STA coordinator, W.H.O - Nigeria and by extension Dr. Kazadi Mulombo (W.R, W.H.O - Nigeria) for finding us worthy for deployment to Ondo state as part of the W.H.O COVID_19 response team. Dr. Terna Nomhwange particularly has been encouraging staff to write scientific papers at any opportunity.

Doctors Rosemary Onyibe, Geoffery Namara and Rex Npazanje together with Prof Bola Olayinka, all of the W.H.O contributed immensely by sharing COVID related literature materials during the regular weekly TC meetings held with all COVID_19 STAs. This enriched our knowledge so much. Thank you. 
Three very intelligent persons namely Itse Olaoye, Dupe Dosumu and Adewale Adejugba ensured the success of this study. They are W.H.O consultants in the same office with the principal researcher. All data used for the analysis could not have been obtained but for their field presence. We particularly appreciate the role of Itse Olaoye for painstakingly reviewing the study protocol.

Finally, many thanks go to Mrs. Sheyifunmi Falana - the disease surveillance and notification officer (DSNO) of the study LGA. It is rare to find a DSNO so full of energy and passion to work like her. She ensured that all planned health facilities were routinely supervised which led to the research concluded in record time!

$7^{\text {th }}$ July, 2021

Author(s) information: The dual of M.Z \& A.F are W.H.O consultants with vast experiences in public health. Aside from being members of the COVID respond team that is directly in-charge in Ondo State, the study area; they are all Nigerian nationals that understand the current realities in the country. M.Z in particular is a researcher at a local university in Nigeria (the Ahmadu Bello University, Zaria) and successfully submitted a research paper to the BMC infectious disease journal last year concerning a 'classical' study on increasing immunization coverage using GIS innovations. A.F taught M.Z nearly one and half decades ago during an MPH program (Field Epidemiology) at the University of Ibadan Nigeria's premier university.

1. O.A is a onetime coordinator of the EU-SIGN, a project that specializes in the delivery of quality routine immunization services in Northern Nigeria. He is a public health expert that has written so many publications on COVID_19.

2. G.F is the state disease surveillance and notification officer (DSNO) for Ondo State. He is an epidemiologist per excellence. He's got nearly one and half decades experience on the job.

3. M.M is the Director of immunization at the national primary health care development agency (NPHCDA), Abuja, Nigeria. He is not only a renowned public health physician but a clinician with very robust clinical experience. He practiced clinical medicine for over 3 decades before joining the public sector.

4. K.T is with the W.H.O at the regional office in Brazzaville, republic of the Congo. He is an expert deep knowledge of the local terrain in Nigeria. He sojourned in Nigeria before and participated in the production of G.I.S drawn maps to support Polio vaccination activities in northern part of the country.

\section{References}

1. Adebayo $O$ Eludoyin et al. Climate events and impact on cropping activities of small-scale farmers in a part of south west Nigeria. Weather climate and society, December 2016.

2. Kwaw Andam, Hyacinth Edeh, Victor Oboh, Karl Pauw and James Thurlow. Impact of COVID_91 on food systems and poverty in Nigeria. Elsevier Public Health Emergency Collection, 2020. 
3. Henry Inegbedion. Impact of COVID_19 on economic growth in Nigeria. Heliyon vol 7 issue 5, May 2021.

4. Temiloluwa Moyosoreoluwa Abikoye et al. collateral damage: the impact of COVID_19 pandemic on the case of a patient with tuberculous neuroretinitis in Lagos, Nigeria. Pan African Medical Journal. 2020; 35 (2) : 135

5. Nwoke Emmanuel et al. Impact of the COVID-19 Pandemic on Consumers' Access to Essential Medicines in Nigeria. The American Journal of Tropical Medicine and Hygiene, 01 Oct 2020

6. Ahmed, T., Rahman, A.E., Amole, T.G. et al. The effect of COVID-19 on maternal newborn and child health $(\mathrm{MNCH})$ services in Bangladesh, Nigeria and South Africa: call for a contextualised pandemic response in LMICs. Int J Equity Health 20, 77 (2021).

7. Zhu, Y., Li, W., Yang, B. et al. Epidemiological and virological characteristics of respiratory tract infections in children during COVID-19 outbreak. BMC Pediatr 21, 195 (2021).

8. Bernhard Michalowsky, Wolfgang Hoffmann, Jens Bohlken, Karel Kostev. Effect of the COVID-19 lockdown on disease recognition and utilisation of healthcare services in the older population in Germany: a cross-sectional study.

9. Hoyer C, Ebert A, Szabo K, Platten M, Meyer-Lindenberg A, Kranaster L. Decreased utilization of mental health emergency service during the COVID-19 pandemic.

\section{Figures}

Figure 1 is available in the supplementary files section.

\section{Figure 1}

Figure 1 is available in the supplementary files section.

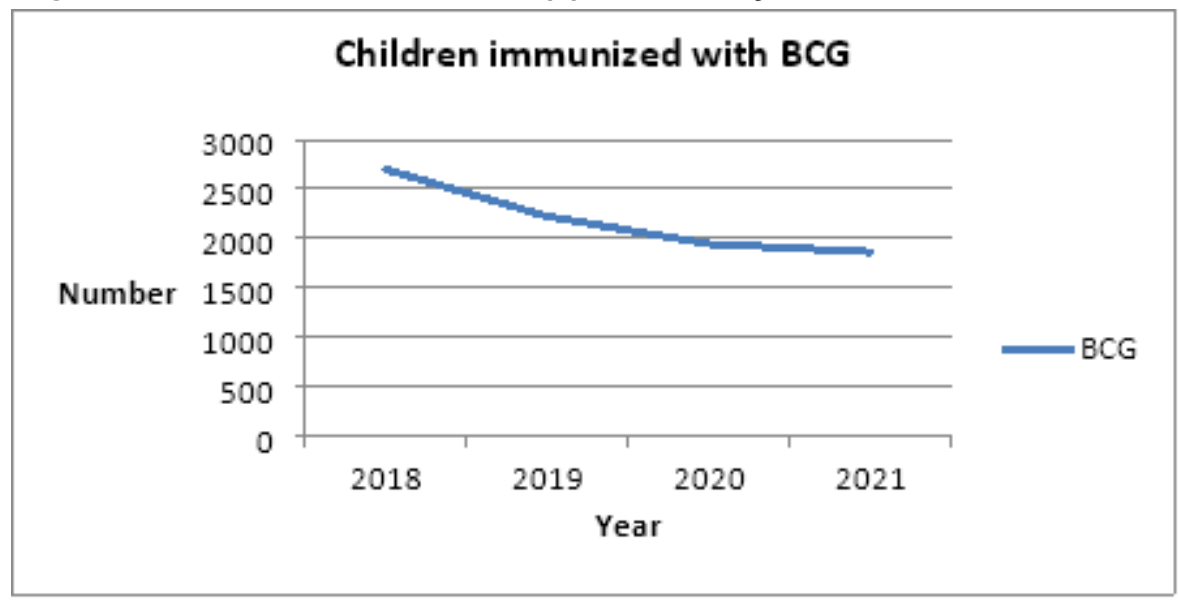

\section{Figure 2}


Trends in number of children reached with BCG.

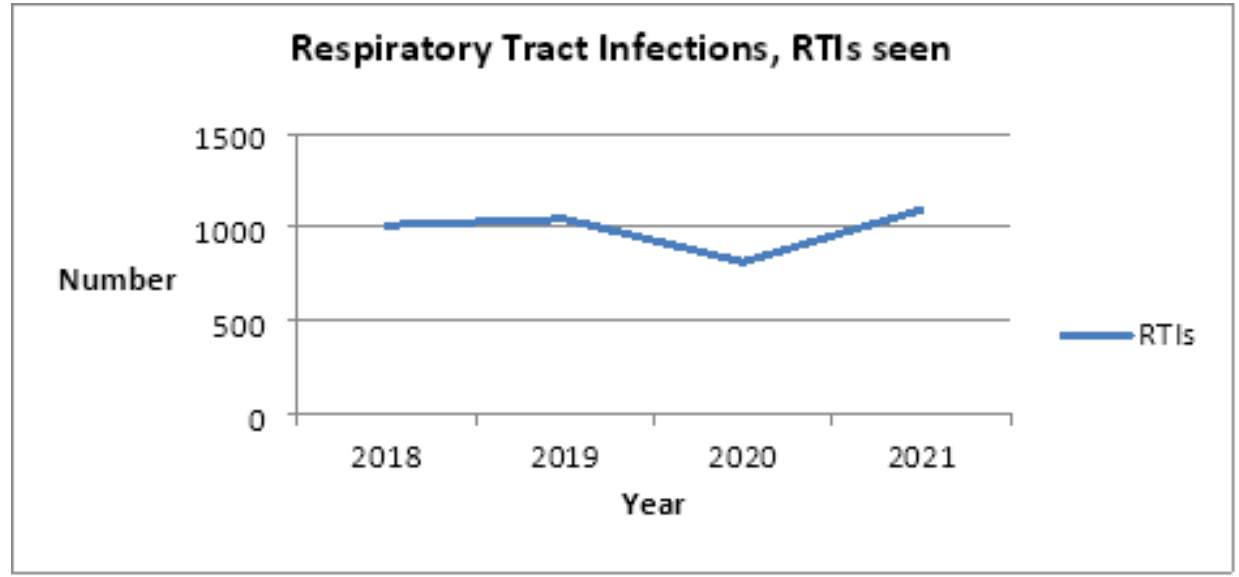

\section{Figure 3}

Trends in the number of RT Is cases seen in the health facilities

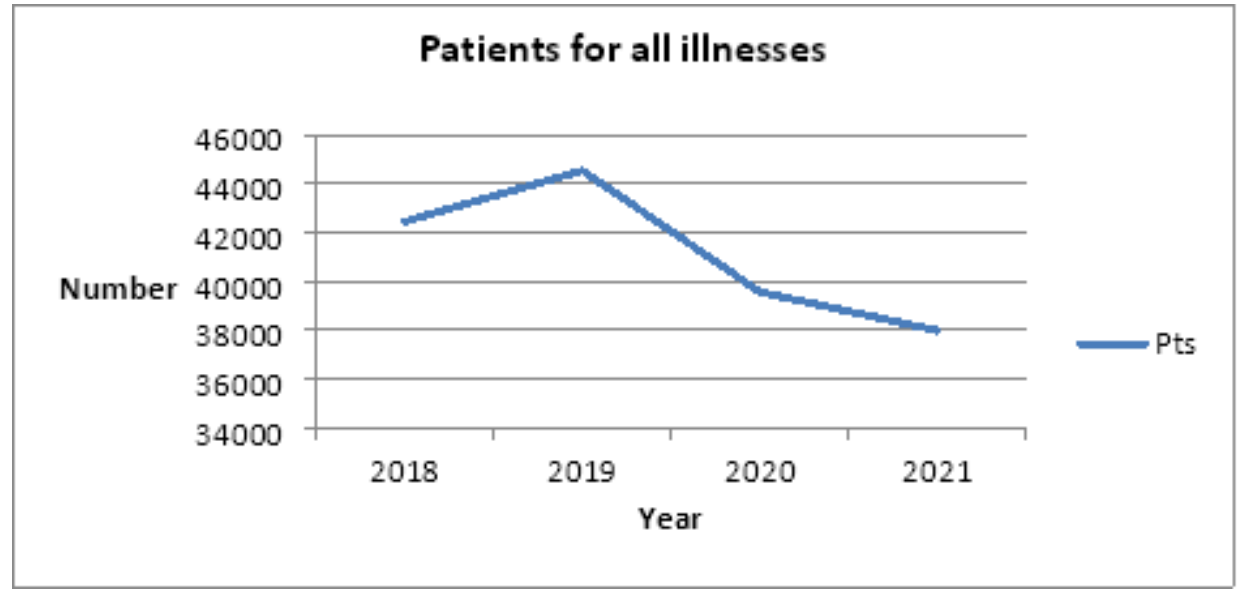

\section{Figure 4}

Trends in the total number of patients (for all purposes) seen at health facilities

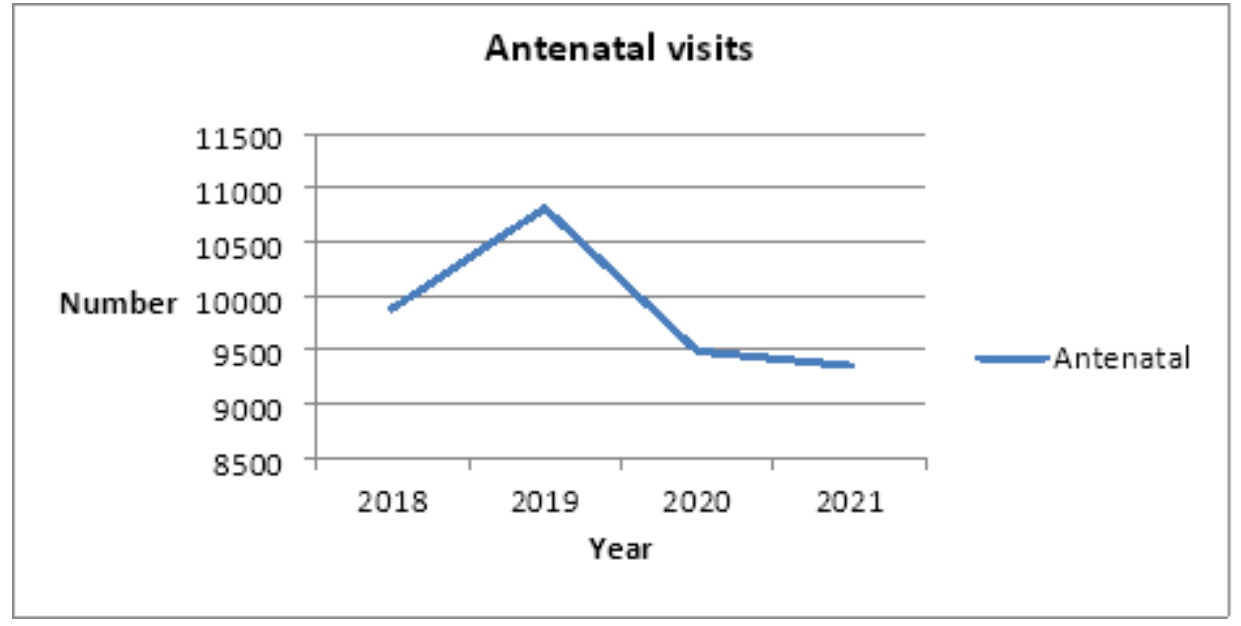

Figure 5 
Trends in antenatal visits.

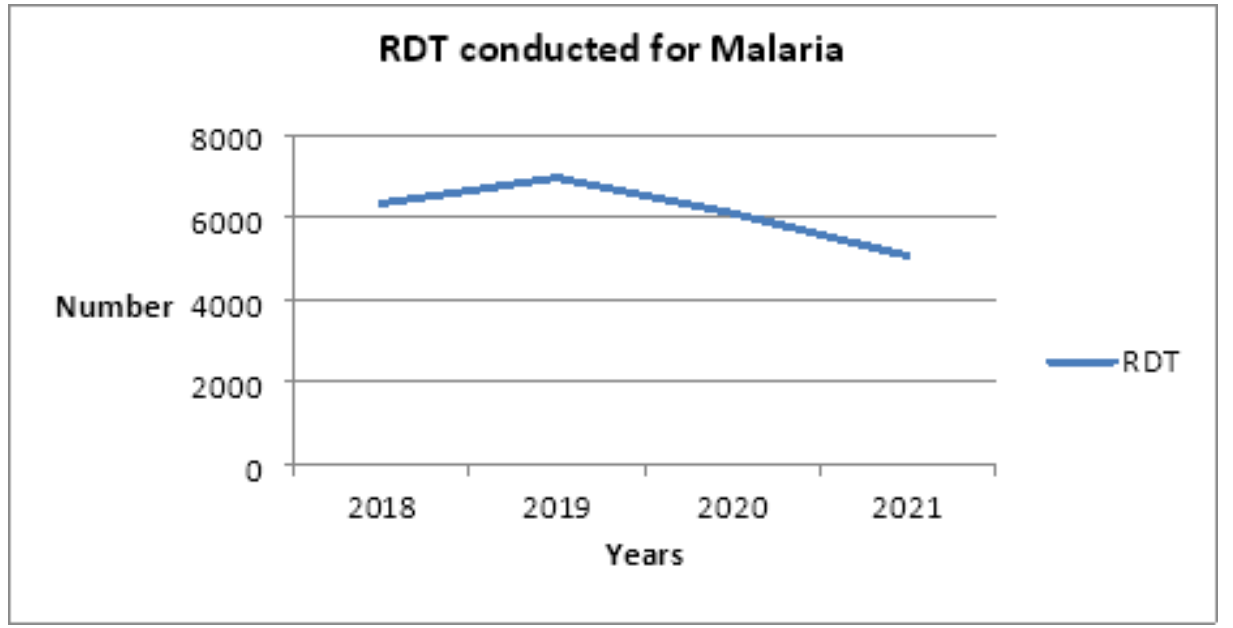

Figure 6

Trends in total number of RDTs recorded.

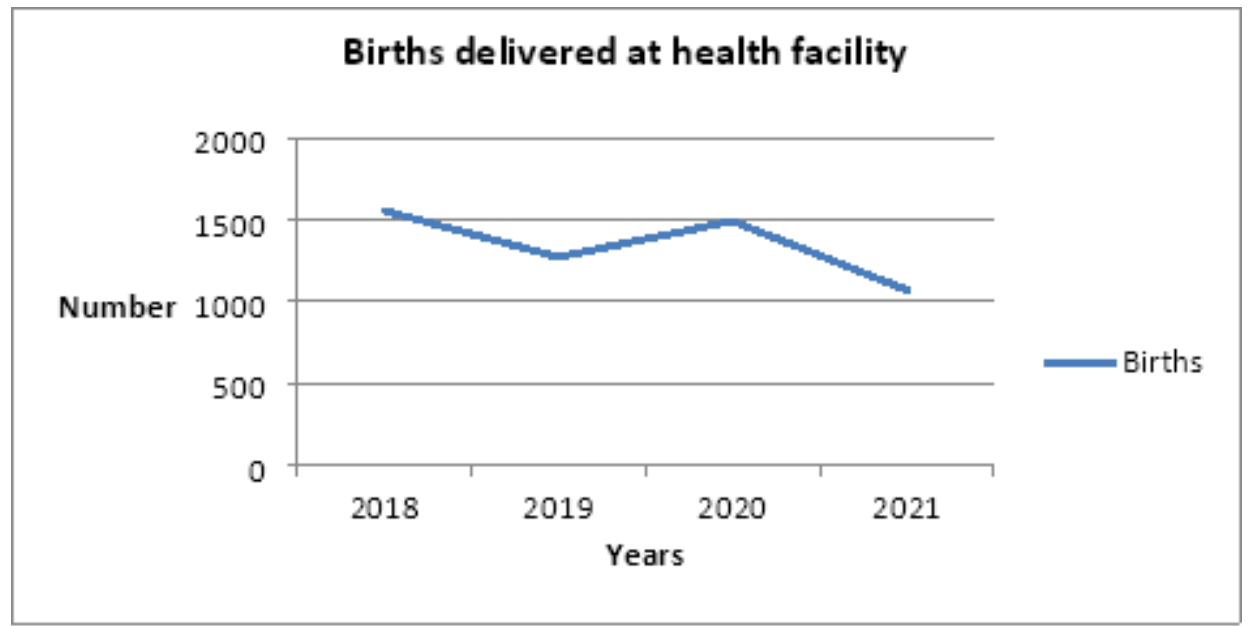

\section{Figure 7}

Trends in live births recorded.

\section{Supplementary Files}

This is a list of supplementary files associated with this preprint. Click to download.

- Figure1DetailresultsobtainedOndocovidstudy.xlsx

- Annex10ndocovidstudyarea.pdf

- Annex2OndostateNigeria.pdf 